\title{
Research on Visualization of Inducer Cavitation of High-Speed Centrifugal Pump in Low Flow Conditions
}

\author{
Zhenfa Xu ${ }^{1,2, *}$, Fanyu Kong ${ }^{1}$, Hongli Zhang ${ }^{1}$, Kun Zhang ${ }^{1}$, Jiaqiong Wang ${ }^{1}$ and Ning Qiu ${ }^{1} \mathbb{D}$ \\ 1 Research Center of Fluid Machinery Engineering and Technology, Jiangsu University, \\ Zhenjiang 212013, China; kongm@ujs.edu.cn (F.K.); 2111511015@ujs.edu.cn (H.Z.); \\ 2211811037@ujs.edu.cn (K.Z.); wangjiaq@ujs.edu.cn (J.W.); qiuning@ujs.edu.cn (N.Q.) \\ 2 School of Mechanical Engineering, Anhui Polytechnic University, Wuhu 241000, China \\ * Correspondence: xuzhenfa@ahpu.edu.cn
}

check for updates

Citation: $\mathrm{Xu}, \mathrm{Z}$;; Kong, F.; Zhang, H.; Zhang, K.; Wang, J.; Qiu, N. Research on Visualization of Inducer Cavitation of High-Speed Centrifugal Pump in Low Flow Conditions. J Mar. Sci. Eng. 2021, 9, 1240. https:// doi.org/10.3390/jmse9111240

Academic Editor: Alon Gany

Received: 28 September 2021 Accepted: 5 November 2021 Published: 8 November 2021

Publisher's Note: MDPI stays neutral with regard to jurisdictional claims in published maps and institutional affiliations.

Copyright: (c) 2021 by the authors. Licensee MDPI, Basel, Switzerland. This article is an open access article distributed under the terms and conditions of the Creative Commons Attribution (CC BY) license (https:// creativecommons.org/licenses/by/ $4.0 /)$.

\begin{abstract}
Inducer is often used to improve the cavitation performance of pump. In order to study the cavitation characteristics of inducer under low flow condition of high-speed pump, high-speed photography technology was employed in this paper to carry out visual experiments on the inducer of a high-speed centrifugal pump. In low flow rates, Cavitation distribution and evolution among the inducer were captured. The experimental results revealed that a band-shaped backflow vortex in the inlet pipe would occur when the flow rate was less than $0.3 \mathrm{Q}_{\mathrm{d}}$. Moreover, the backflow vortex in the inlet pipe rotated with the inducer and the rotational speed of backflow vortex was approximately half of the inducer. The visualization test of $0.27 \mathrm{Q}_{\mathrm{d}}$ was carried out: when the NPSH was greater than $6.72 \mathrm{~m}$, the bubbles in the inlet pipe were asymmetrical; When the NPSH dropped to $5.41 \mathrm{~m}$, the cavitation was becoming less asymmetrical; When NPSH dropped to $3.81 \mathrm{~m}$, cavitation evolved to the deteriorating stage, plenty of bubbles entered into the main impeller, resulting in a rapid decline of pump performance. Furthermore, the cavitation performance was worse at an extreme flow rate, and the NPSH value of $0.27 \mathrm{Q}_{\mathrm{d}}$ was $7.5 \%$ greater than that under design condition.
\end{abstract}

Keywords: inducer; cavitation; visual experiments; net positive suction head (NPSH); backflow vortex

\section{Introduction}

Cavitation causes a decrease in the performance of the centrifugal pump, which is an explicit affection to the high-speed centrifugal pump. Installing an inducer in front of the main impeller is a common method for improving the cavitation performance of high-speed centrifugal pumps. Therefore, the anti-cavitation performance of the centrifugal pump can be reinforced through improving the pressure in the suction side of the impeller.

Many scholars have investigated cavitation in the inducer by utilizing different approaches via numerical simulation and experimental investigations. Some of them have studied the influence of geometric parameters of the inducer on cavitation behavior. For instance, Bakir et al. [1] have obtained five sets of experimental results of different inlet edge shapes by cutting the original inducer blade. Moreover, the authors have analyzed the effect of the inlet edge shape on the cavitation performance of the inducer. By comparing experimental results of the three-blade and five-blade inducer, Olivier et al. [2] have proposed the effect of the number of blades on the cavitation behavior of the inducer. Cheng et al. [3] have performed numerical calculations on inducers with eight different sweepback angles. The calculation results show that the net positive suction head (NPSH) is related to sweepback angle. NPSH gradually decreases when sweepback angle is from $120^{\circ}$ to $270^{\circ}$, and gradually increases when sweepback angle is from $270^{\circ}$ to $290^{\circ}$.

Tip clearance has a significant effect on the cavitation of the inducer [4-6]. Okita et al. [4] have found that under the action of pressure difference, the tip clearance of the inducer produces backflow vortex cavitation. Moreover, the authors have observed that the rotational speed of the backflow vortex cavitation was slower than the inducer. Kim et al. [6] 
performed numerical calculations on the inducer flow fields of three different tip clearances. The results show that cavitation has a minor effect on static pressure distribution, and a larger tip clearance leads to an increase in the tip leakage vortex cavitation. This type of cavitation causes the pump head to drop rapidly when the NPSH is relatively small.

To analyze the influence of thermal effects on the cavitation of the inducer, Franc et al. [7] and Ehrlich et al. [8] have conducted visualization experiments at different temperatures. Guo et al. [9] have designed five types of inducers with different short blade positions and analyzed the influence of short blade positions on the cavitation and performance of pump. The results show that the position of the short blades has little impact on the performance of the pump, yet has a significant effect on cavitation performance. To suppress cavitation in the inducer, Choi et al. [10] have designed J-Grooves which were installed in the inlet pipe of the leading edge of the inducer blade. Inducer cavitation causes vibration and affects the operation stability of the pump unit. Researchers have used the combination of transient pressure signal measurements and visual experiments to study the cavitation instability of the inducer [11-13].

On the other hand, scholars have studied the cavitation evolution in the inducer. Tsujimoto et al. [14] have employed high-speed photography to capture the backflow vortex cavitation phenomenon of the inducer under the design condition. Yu et al. [15] predict the number of backflow vortexes of axial flow pumps and verify it through the inducer's visual experiment. The results express that theoretical prediction highly corresponds to the experimental results within a certain parameter range. Nobuhiro et al. [16] obtained the backflow vortex structure through the large eddy simulation method and found that the backflow vortex rotates with the inducer at approximately half speed of the inducer. As the flow rate decreased, the backflow vortex diffused in the upstream direction. Tani et al. [17] discussed cavitation behavior under different flow conditions. The results show that the backflow is weakened when the flow coefficient is larger. Meanwhile, the authors have also studied the relationship between the attack angle and the backflow. Choi et al. [18] employed numerical and experimental methods to study the cavitation of an inducer with a bearing bracket. He reveals that the cavitation performance cannot simulate with a simple cavitation model. The results show that when the pump operates at designed conditions, the backflow vortex disappears at the leading edge when the inlet pressure reduces further. Cui et al. [19] conducted experiments and simulations under the air-water two-phase conditions of the inducer and have found that the gas content of the incoming flow has a significant impact on the low flow conditions. Furthermore, the author observes that a suitable gas content is beneficial for improving the cavitation performance of the inducer. Huan et al. [20] have combined simulation and visual experiments to study the cavitation evolution of an inducer under the design condition. Ito et al. [21] compared cavitation characteristics of liquid nitrogen with water at different temperatures, and found that the backflow vortex cavitation also occurs in the two kinds of fluid, and the volume of the backflow vortex is increased with the flow rate and NPSH decreasing. However, cavitation in liquid nitrogen is foggy, while in the water it is foamy, respectively.

The existing literature on inducer cavitation mainly focuses on the flow range around the design condition [18-20]. Yu. et al. [15] and Tani et al. [17] have discussed the cavitation of the inducer under different flow conditions. They have found that the distribution of bubbles in the inducer is different at different flow rates, and the flow rate has a significant impact on the cavitation evolution of the inducer. For some special occasions, pumps may operate under extreme conditions, therefore full working condition research is required. There are few reports on inducer cavitation evolution research under extremely low flow conditions. The mechanism of cavitation of inducer under low flow condition is not clear. This paper explores the cavitation development of inducer under the flow rate at $0.3 Q_{d}$ and below.

High-speed photography technology is considered to be a very effective method to study cavitation mechanisms [14,22]. The pipeline or pump casing is made of plexiglass, and the high-speed camera can synchronously capture the flow information in the pump. 
When cavitation occurs, the bubble developing process will be clearly captured by a highspeed camera. Therefore, many scholars use high-speed photography technology to study the cavitation of inducer [19-21].

In this paper, high-speed photography technology was utilized to carry out visual experiments of an inducer. The backflow vortex in the inlet pipe under low flow conditions was captured. The distribution of bubbles in the inducer and inlet pipe of different NPSH were obtained. Based on the visual experiment results, the cavitation evolution under low flow conditions, asymmetric cavitation phenomenon in the inducer, and the effect of cavitation on the pump performance were well-analyzed.

\section{Research Object}

The research object of this paper was a compact high-speed magnetic pump with an inducer, as shown in Figure 1. The design parameters were $Q_{d}=30 \mathrm{~m}^{3} / \mathrm{h}, \mathrm{H}=130 \mathrm{~m}$, $\mathrm{n}=8000 \mathrm{r} / \mathrm{min}$, and $\mathrm{P}=22 \mathrm{kw}$. A variable-pitch inducer was used within the pump. Due to the small overall size, the inducer was designed in the form of two blades. The design parameters of the inducer are shown in Table 1.

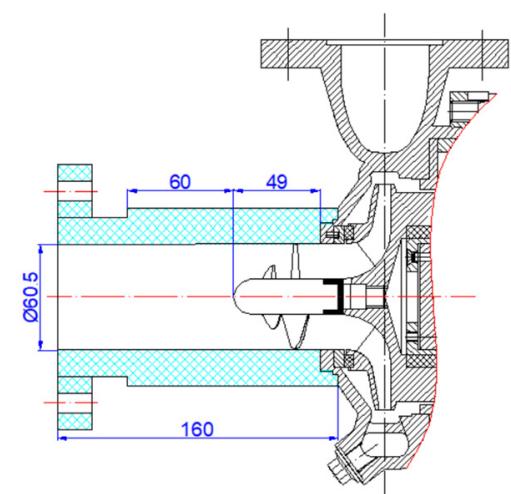

(a) 2D sketch of test pump

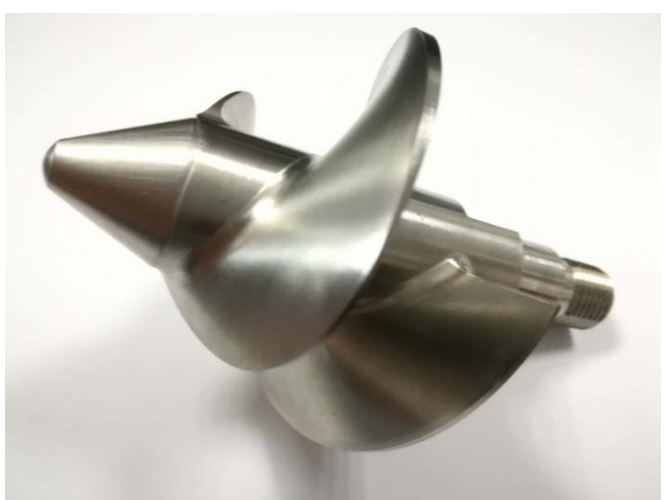

(b) Test inducer

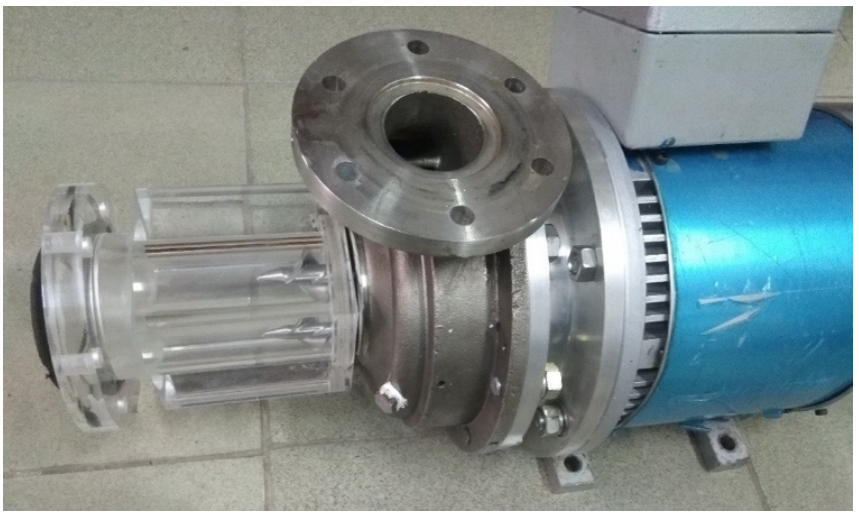

(c) Test pump

Figure 1. High-speed magnetic drive centrifugal pump.

Table 1. Design parameters of the inducer.

\begin{tabular}{cc}
\hline Parameter & Value \\
\hline Blade tip diameter $/ \mathrm{mm}$ & 58.8 \\
Hub diameter $/ \mathrm{mm}$ & 20 \\
Number of blades & 2 \\
Sweepback angle of leading edge $/{ }^{\circ}$ & 178.9 \\
Axial length $/ \mathrm{mm}$ & 37.4 \\
\hline
\end{tabular}


To increase the visibility of the inducer, the inlet flange of the original pump casing was cut off. Then, a transparent plexiglass pipe was installed at the front of the pump casing. The cavitation evolution of the inducer was captured by a high-speed camera.

\section{Numerical Method}

\subsection{Continuity Equation and Momentum Equation}

In the simulation, the vapor-liquid two-phase flow was generally assumed to be homogeneous. The Navier-Stokes equation based on the Newtonian fluid was used in this simulation. The equation was formulated in the Cartesian coordinate system as: [23]

$$
\begin{gathered}
\frac{\partial \rho_{m}}{\partial t}+\frac{\partial\left(\rho_{m} u_{j}\right)}{\partial x_{j}}=0 \\
\frac{\partial\left(\rho_{m} u_{i}\right)}{\partial t}+\frac{\partial\left(\rho_{m} u_{i} u_{j}\right)}{\partial x_{j}}=-\frac{\partial p}{\partial x_{i}}+\frac{\partial}{\partial x_{j}} \times\left[\left(\mu+\mu_{T}\right)\left(\frac{\partial u_{i}}{\partial x_{j}}+\frac{\partial u_{j}}{\partial x_{i}}-\frac{2}{3} \frac{\partial u_{i}}{\partial x_{j}} \delta_{i j}\right)\right] \\
\frac{\partial \rho_{l} \alpha_{l}}{\partial t}+\frac{\partial\left(\rho_{l} \alpha_{l} u_{j}\right)}{\partial x_{j}}=m^{+}+m^{-} \\
\rho_{m}=\rho_{l} \alpha_{l}+\rho_{v} \alpha_{v} \\
\mu_{m}=\mu_{l} \alpha_{l}+\mu_{v} \alpha_{v}
\end{gathered}
$$

where the subscript $i, j$ indicates the coordinate direction, $u$ indicates the velocity, $p$ indicates the pressure, $\rho_{l}$ indicates the liquid density, $\rho_{v}$ indicates the vapor density, $\alpha_{v}$ indicates the vapor volume fraction, $\alpha_{l}$ indicates the liquid volume fraction, $\mu_{l}$ indicates the liquid laminar viscosity, $\mu_{v}$ indicates the vapor laminar viscosity, $\mu_{T}$ indicates the turbulent viscosity, $m^{+}$indicates the vapor condensation rate, and $m^{-}$indicates the vapor evaporation rate. $\rho_{m}$ denotes vapor-liquid mixed-phase density, $\mu_{m}$ denotes vapor-liquid mixed-phase laminar viscosity, $t$ indicates the time, $x_{i}, x_{j}$ are the coordinates in the $i$ and $j$ directions, and $\delta_{i j}$ indicates the shear stress.

\subsection{Cavitation Model}

Zwart model [24] is a cavitation model based on the mass transport equation, which describes the cavitation phase change process mainly by establishing the transport relationship between the vapor and liquid phases. Its evaporation rate and condensation rate are defined as follows:

$$
\begin{gathered}
m^{+}=C_{\text {dest }} \frac{3 \alpha_{n u c}\left(1-\alpha_{v}\right) \rho_{v}}{R_{B}}\left(\frac{2}{3} \frac{p_{v}-p}{\rho_{l}}\right)^{1 / 2}, p<p_{v} \\
m^{-}=-C_{\text {prod }} \frac{3 \alpha_{v} \rho_{v}}{R_{B}}\left(\frac{2}{3} \frac{p-p_{v}}{\rho_{l}}\right)^{1 / 2}, p>p_{v}
\end{gathered}
$$

In the formula, $R_{B}$ is the bubble radius, $\alpha_{n u c}$ is the volume fraction of gas nuclei, $p_{v}$ is the saturated vapor pressure, $C_{\text {prod }}$ is the rate of steam condensation when the local static pressure is greater than the saturation steam pressure, and $C_{\text {dest }}$ is the rate of steam evaporation when the local static pressure is lower than the saturated vapor pressure. The values of the coefficients in the model are:

$$
R_{B}=1 \times 10^{-6} m, C_{\text {prod }}=0.01, C_{\text {dest }}=50, \alpha_{n u c}=1 \times 10^{-4}
$$

\subsection{Numerical Setup and Grid Validation}

The NX software was used to model the flow domain of the high-speed magnetic pump. The full flow field of the high-speed magnetic pump was divided into seven calculation domains: inlet section, inducer, impeller, volute, outlet section, front pump cavity, and back pump cavity. The entire computational domain is shown in Figure 2a. The 
ICEM-CFD software was used to mesh each computational domain. The inducer domain was meshed by unstructured method, and the rest of the computational domains were set structured grids. The mesh quality affected the calculation accuracy [25,26], the mesh for all domains was checked through the independence test, as summarized in Table 2. A scheme of grid was applicated with the number of 2.5 million. The mesh number of different domains is shown in Table 3 . Figure $2 b$ shows the mesh detail of calculation domain [27-29].

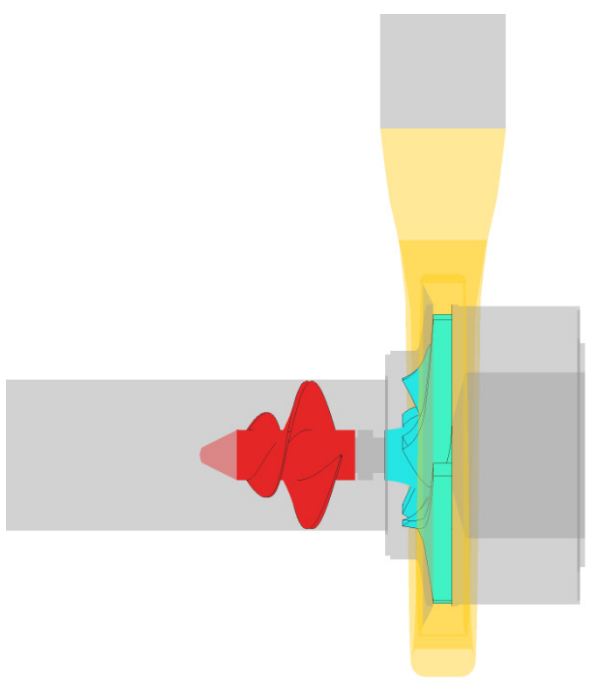

(a) Computational domain

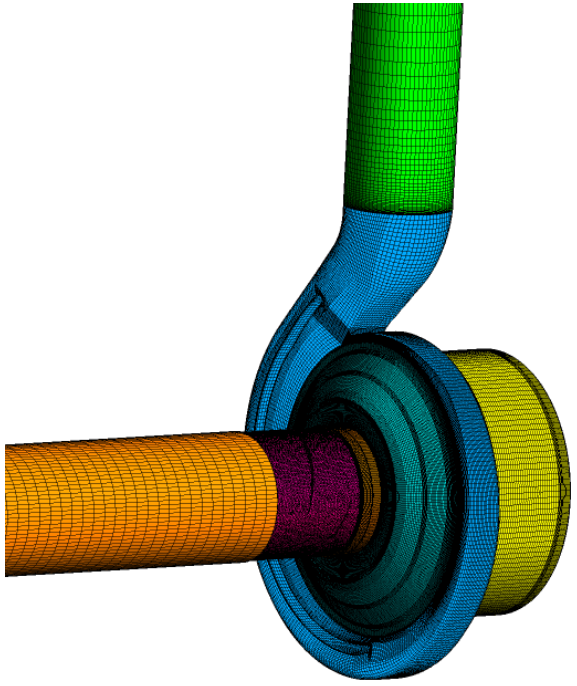

(b) Mesh of computational domain

Figure 2. Computational domain model and grid of pump.

Table 2. Mesh independence verification test.

\begin{tabular}{ccc}
\hline No. of Cells & Head $/ \mathbf{m}$ & Difference in Head $/ \%$ \\
\hline $1,226,030$ & 137.56 & 1.4 \\
$1,671,438$ & 136.19 & 0.2 \\
$2,536,247$ & 136.2 & 0.2 \\
$3,790,004$ & 136.22 & 0.2 \\
\hline
\end{tabular}

Table 3. Mesh No. of each domain.

\begin{tabular}{cccccccc}
\hline Domain & Inducer & Impeller & Volute & Inlet Section & Infront Cavity & Outlet Section & Back Cavity \\
\hline No. of cells & 561,306 & 614,600 & 361,840 & 206,976 & 340,470 & 82,555 & 368,500 \\
\hline
\end{tabular}

The k-epsilon $(k-\varepsilon)$ turbulence model was usually used in rotating machinery $[30,31]$. It has the characteristics of fast convergence and high precision. In this paper, the $\mathrm{k}-\varepsilon$ turbulence model was used in simulation. The inlet condition was set as total pressure with $1 \mathrm{~atm}$ and turbulence intensity was $5 \%$. The mass flow of $8.66 \mathrm{~kg} / \mathrm{s}$ was set at outlet. Further, all walls were set as No Slip Wall.

\section{Test Setup}

Visual and performance experiments of a high-speed magnetic pump were carried out on the closed-loop high-speed pump test rig, which was composed of a water tank, inlet and outlet pipes, inlet and outlet valves, turbine flowmeters, pressure transmitters, vacuum pumps, and control cabinets. A schematic diagram of the test rig is shown in Figure 3. The pump head was calculated by measuring the inlet and outlet pressures of the pump. YB131 pressure transmitters, with ranges of $0.1-1 \mathrm{MPa}$ and $0-1.6 \mathrm{MPa}$, were selected for the inlet and outlet pressure measurement. The measurement accuracy of pressure 
transmitters was $\pm 0.5 \%$. The turbine flowmeter installed on the outlet pipe was used to measure the pump flow. The employed flowmeter was the LWGY DN50 turbine flowmeter with a measurement accuracy of $\pm 0.5 \%$. To adjust the inlet pressure of the pump during the period of testing, the vacuum pump was connected to the water tank.

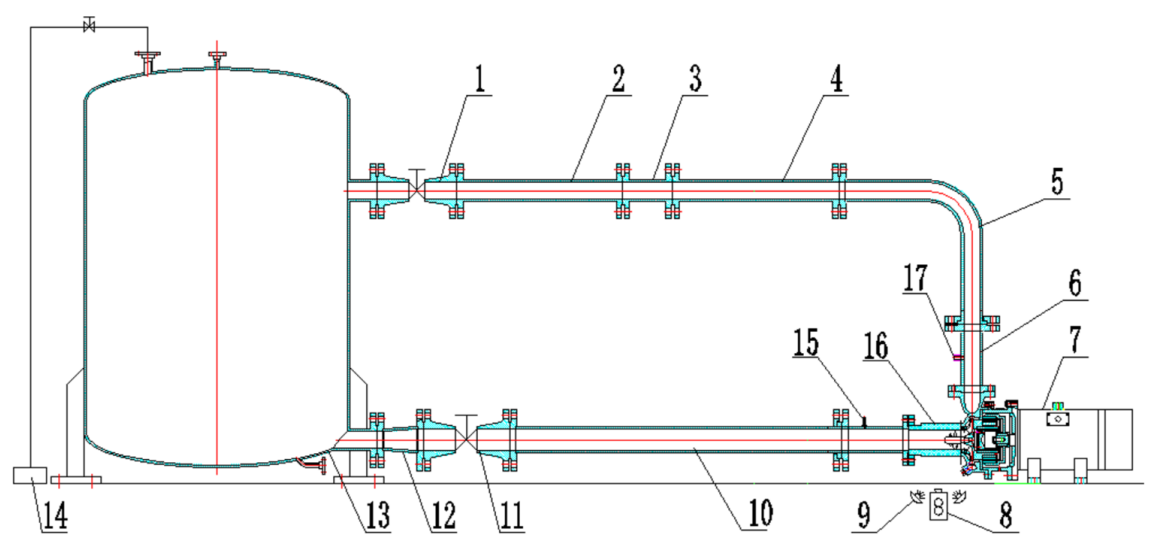

1-Outlet valve, 2, 4, 5, 6-Outlet pipe, 3-Flowmeter, 7-Test pump, 8-High-speed camera, 9-LED light source, 10-Inlet pipe, 11-Inlet valve, 12-Inlet reducer, 13-Water tank, 14-Vacuum pump, 15-Inlet pressure sensor, 16-Plexiglass transparent pipe, 17-Outlet pressure sensor.

Figure 3. Schematic diagram of the test rig.

The high-speed camera system included an IDT Y4 S1 high-speed industrial camera, high-brightness LED light sources, and a data acquisition system. ID T Y4 S1 high-speed camera had a frame rate of $3000 \mathrm{fps}$ with a resolution of 1024 pixels $\times 1024$ pixels and a minimum exposure time of $1 \mu \mathrm{s}$. The Kowa LM16HC lens was applied to conduct the visual experiment, and aperture was $\mathrm{f} / 2$. During the experiment, the frame rate was $3000 \mathrm{fps}$, and the exposure time was $331 \mu \mathrm{s}$. The high-speed camera was placed on the side of the test bench and was perpendicular to the inlet pipe. To improve the clarity of shooting and capturing the evolution of bubbles in the inducer, two high-brightness LED light sources were placed on the same side of the camera during the visual experiment.

The interior structure of the plexiglass pipe was round and, correspondingly, the exterior formation was square. Before the experiment, the camera position was adjusted for well captured bubble phenomenon. The camera lens was perpendicular to the inlet pipe. When the test was ready, the lens was focused, and the frame rate, as well as the exposure time, were set within the software. The test speed of the pump was $8000 \mathrm{r} / \mathrm{min}$, and the vacuum pump was used to adjust the inlet pressure of the pump. The visual experiments under different NPSH were carried out. The visual test rig is shown in Figure 4.

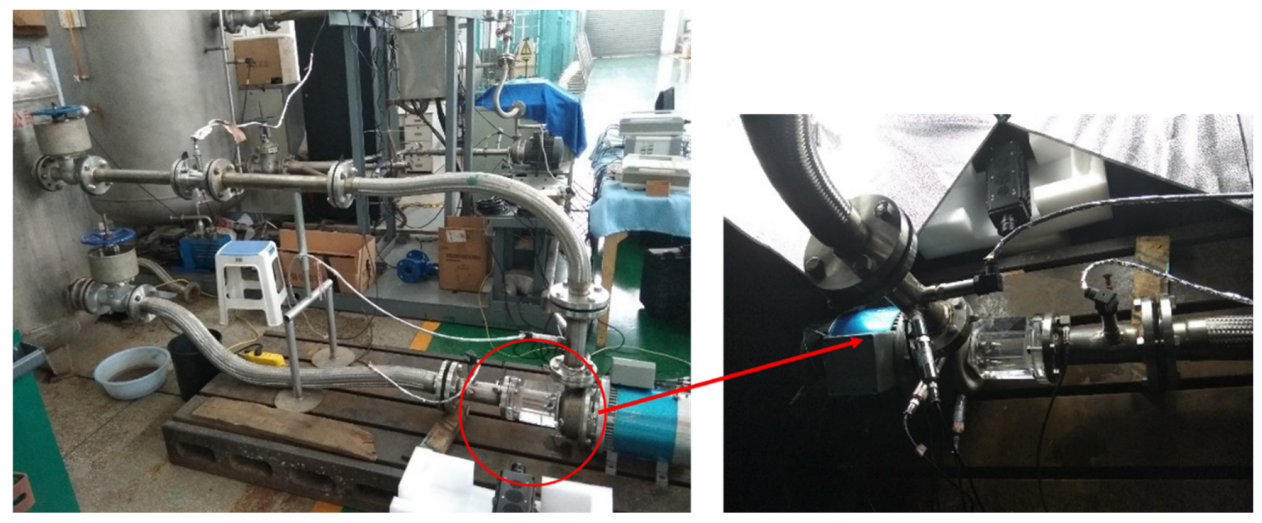

Figure 4. Visual test rig. 


\section{Analysis of the Experimental Results}

\subsection{Performance Curve of High-Speed Magnetic Pump}

The performance curve of the high-speed magnetic drive pump is shown in Figure 5. The simulation efficiency and the test efficiency cannot be compared because the simulation one was just the hydraulic efficiency, while the test one was the efficiency of the unit. Only the head of the test and the simulation are compared in Figure 5. At the design flow, the test head of the pump was $135.9 \mathrm{~m}$, and the efficiency was $34.59 \%$. The performance of the pump corresponds to the design requirement. The head from simulation under the design flow conditions was $136.2 \mathrm{~m}$. The head from simulation under the design flow conditions was $136.2 \mathrm{~m}$. The difference of the head between simulation and experiment was $0.2 \%$. The calculation error became larger at off design condition, the calculation error under large flow rate was $2.3 \%$, while under the small flow rate it was $2.4 \%$.

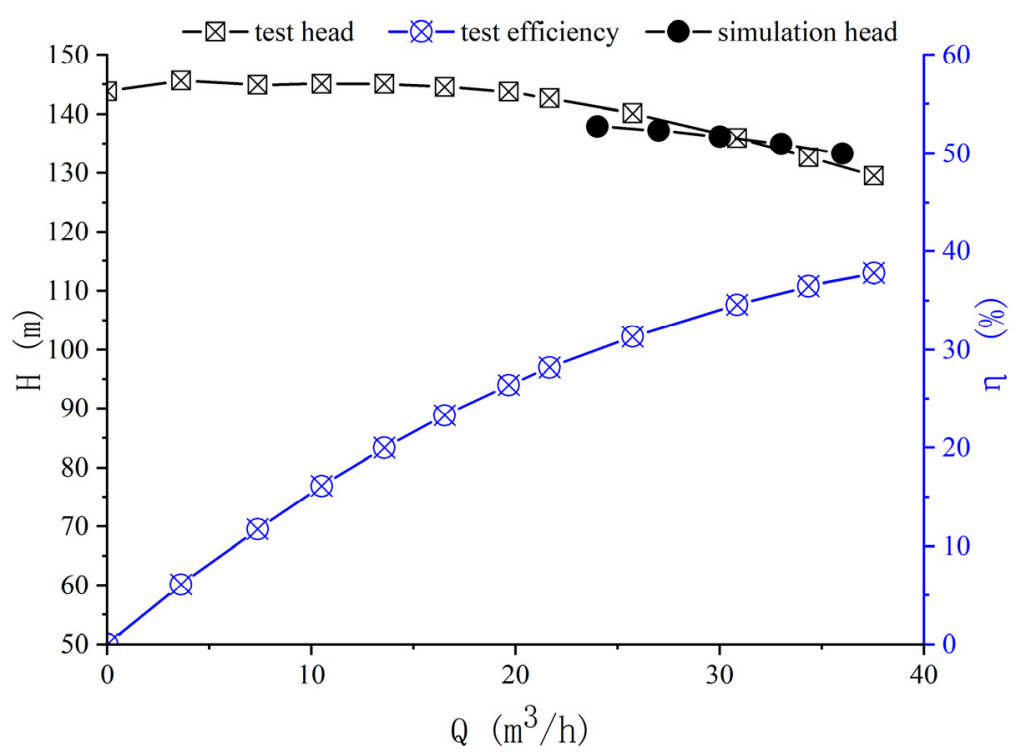

Figure 5. Comparison of simulation and experimental results.

\subsection{Analysis of the Backflow Vortex}

When the magnetic drive pump was operating under low flow condition, a long band-shaped backflow vortex appeared in the inlet pipe which went from the inlet pipe to the leading edge of the inducer blade. This phenomenon appeared at a low flow rate, yet is not obvious under large flow condition. This section will analyze the causes of the formation of the vortex.

A cross-sectional streamline diagram in the inducer is shown in Figure 6, and its background represents the static pressure distribution. When the inducer rotated at high speed, a pressure difference existed between the suction surface and the pressure surface of the blade. Meanwhile, there was a gap between the outer edge of the inducer and the inlet pipe. Due to the pressure variance, tip leakage vortex was formed at the leading edge of the inducer [14]. The pressure difference between the pressure surface and the suction surface increased when the flow rate of the pump decreased. In addition, attack angle of the blade increased with the flow rate decreased. Consequently, the tip leakage vortex at the tip clearance spread in the upstream direction, which induced a backflow vortex forming at the leading edge of the inducer.

In Figure 7, visual images of the inducer are demonstrated. Figure 7a,b represent the inducer operating under $0.1 \mathrm{Q}_{\mathrm{d}}$ and $0.7 \mathrm{Q}_{\mathrm{d}}$, respectively. Obviously, a band-shaped backflow vortex in the inlet pipe is observed at $0.1 Q_{d}$, which is extended to one of the inducer blades on leading edge. However, this phenomenon did not occur on the other blade. When the flow rate was $0.7 Q_{d}$, the length of the backflow vortex was shorter compared with $0.1 \mathrm{Q}_{\mathrm{d}}$. Backflow vortex only existed at the leading edge of the inducer, 
which indicated that the backflow vortex diffused to the upstream significantly when pump operated at low flow rate.

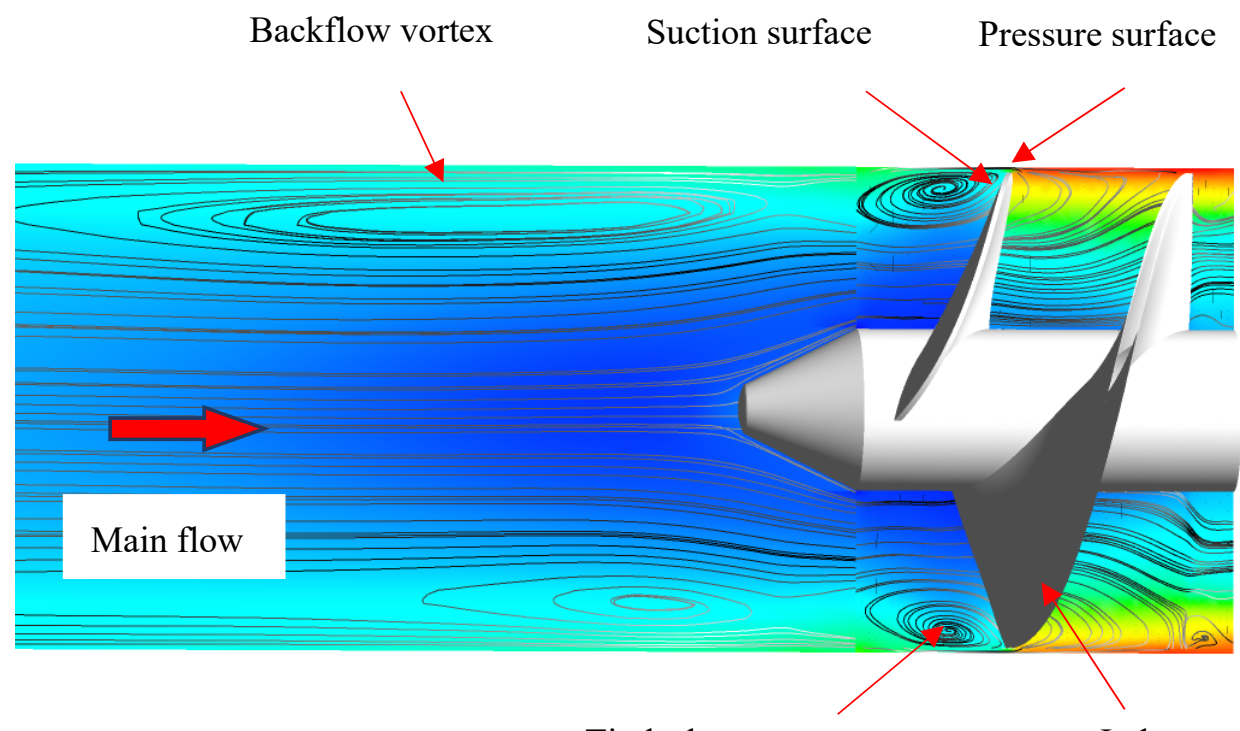

Tip leakage vortex

Inducer

Figure 6. Streamline diagram in the inducer under $Q=0.3 Q_{d}$.

Backflow vortex

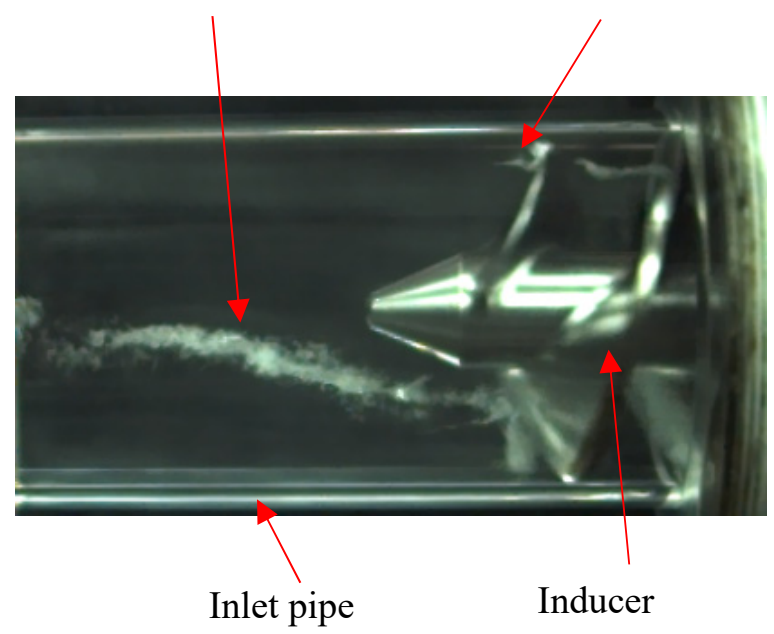

(a) $0.1 Q_{d}$
Backflow vortex

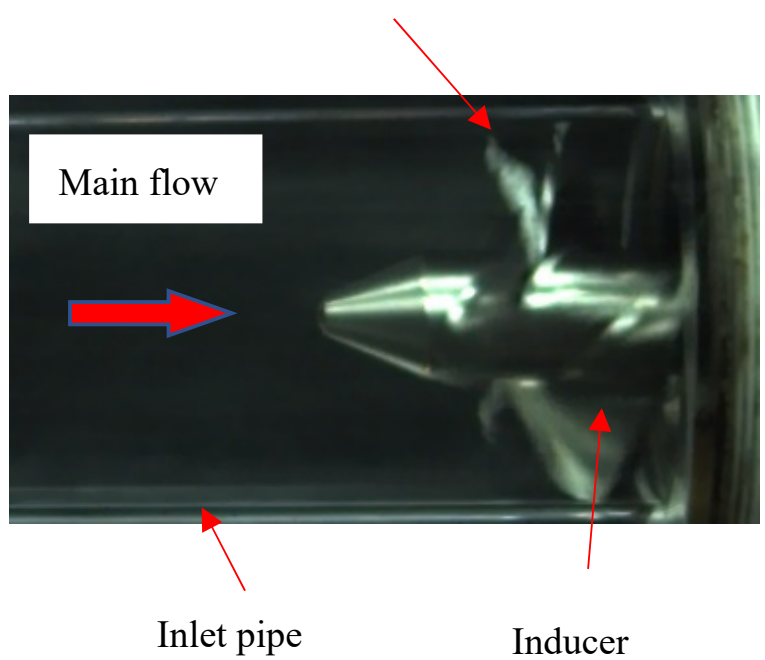

(b) $0.7 Q_{d}$

Figure 7. Visual image of the inducer under NPSH $=10 \mathrm{~m}$.

In Figure 8, a schematic diagram of the internal flow under two different flow conditions is shown. The lines represent three-dimensional streamlines. The grey transparent part is the vorticity contour surface, and the vortex at the outer edge is greater than the center of the pipe. The red curve indicates the area affected by the backflow vortex, which is close to the marginal area of the inlet pipe.

Due to the complexity of the flow in the pump at the low flow rate of $0.1 \mathrm{Q}_{\mathrm{d}}$, there was a larger error in the numerical simulation results compared with the experimental results. The simulation results at $0.3 Q_{d}$ and $0.7 Q_{d}$ were provided for comparison. The results of the two flow conditions are depicted in Figure 8. 


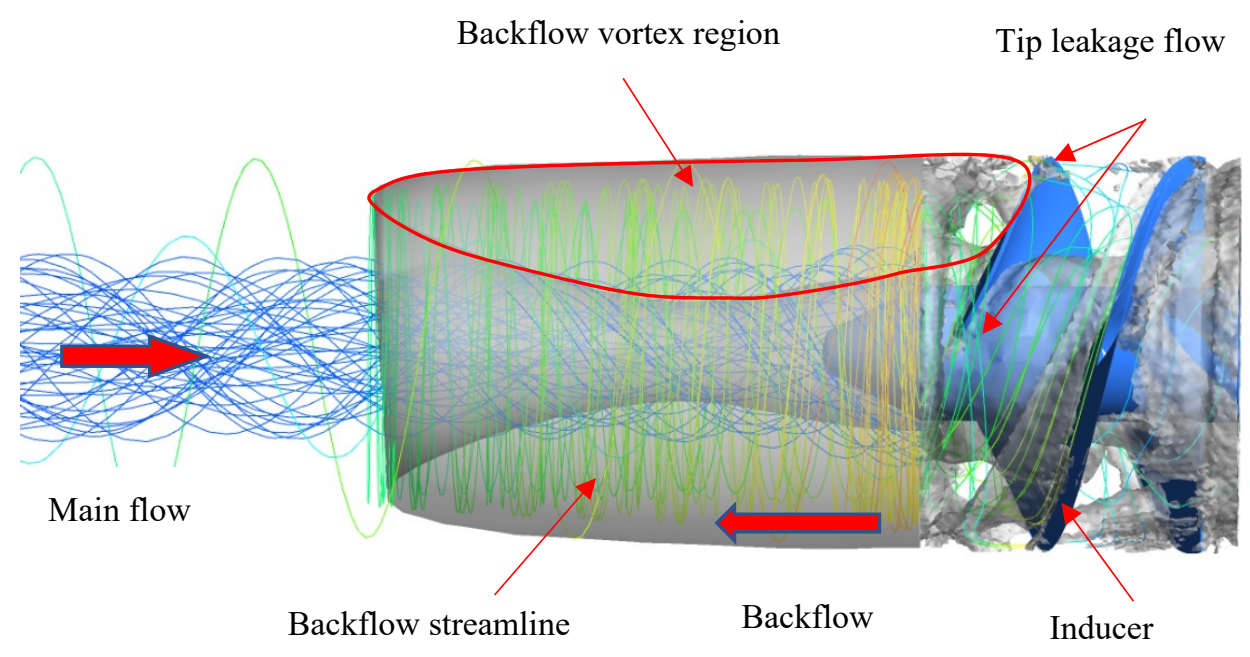

(a) $Q=0.3 Q_{d}$ and swirling strength $=344 \mathrm{~s}^{-1}$

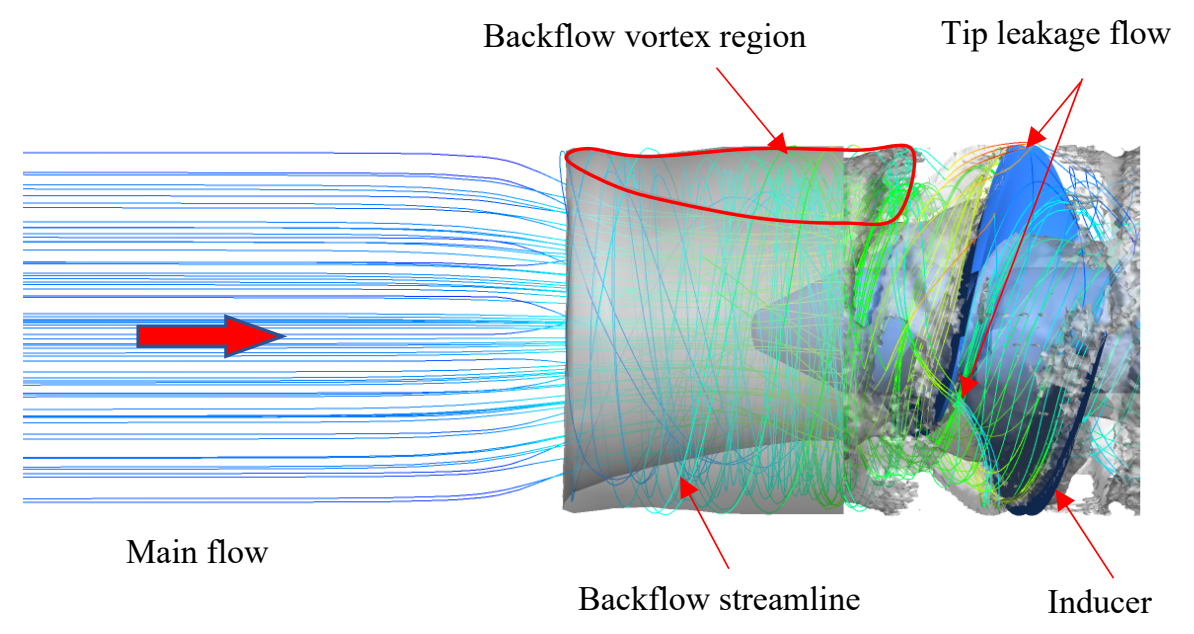

(b) $Q=0.7 Q_{d}$ and swirling strength $=211 \mathrm{~s}^{-1}$

Figure 8. Schematic diagram of the internal flow of the inducer.

The tip leakage phenomenon was captured at both flow conditions. The tip leakage vortex cavitation occurred at the outer edge of the inducer. When the flow rate decreased, the tip leakage flow diffused upstream along the inlet pipe. Finally, it merged with the main flow, then flew back to the inlet of the inducer again. Thus, a backflow vortex which extended from the leading edge of the inducer to the inlet pipe was formed. The area affected by the backflow vortex increased with flow rate reduction. It was observed that the area affected by the backflow vortex at $0.3 \mathrm{Q}_{\mathrm{d}}$ was larger than $0.7 \mathrm{Q}_{\mathrm{d}}$. Furthermore, a low-pressure zone existed at the vortex core of the backflow vortex, which induced local cavitation at the vortex core. The vortex region that extended from the inlet pipe to the leading edge of the inducer is shown in Figure 7. This phenomenon is a typical backflow vortex cavitation.

Visual experimental results of different flow rates are shown in Figure 9. According to the resuts, it can be concluded that the backflow vortex appearing in the inlet pipe is related to the flow rate. According to Figure 9, an obvious backflow vortex in the inlet pipe appears at several flow rates, and the rotating direction of the vortex is the same as the inducer. With flow rate increasing, the diameter of the vortex in the inlet pipe gradually decreases. When the flow rate is up to $0.3 Q_{d}$, the vortex almost disappears, and the strip does not appear when the flow rate is increasing. A single long vortex in the inlet pipe 
is an uncommon phenomenon when the high-speed pump operates under a lower flow condition. Moreover, similar phenomenon was not observed under a larger flow condition.

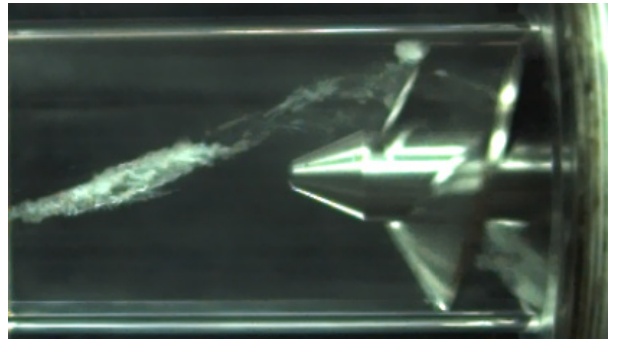

(a) $\mathrm{Q}=0.14 \mathrm{Q}_{\mathrm{d}}$

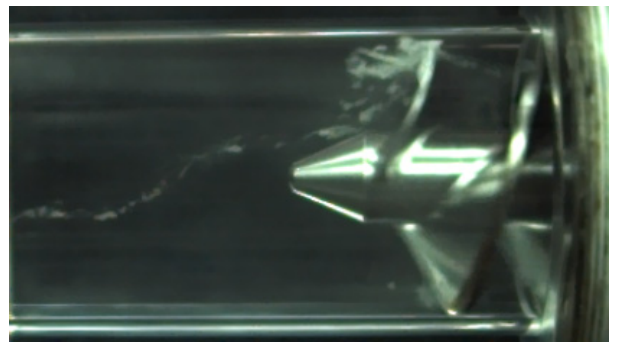

(c) $\mathrm{Q}=0.25 \mathrm{Qd}_{\mathrm{d}}$

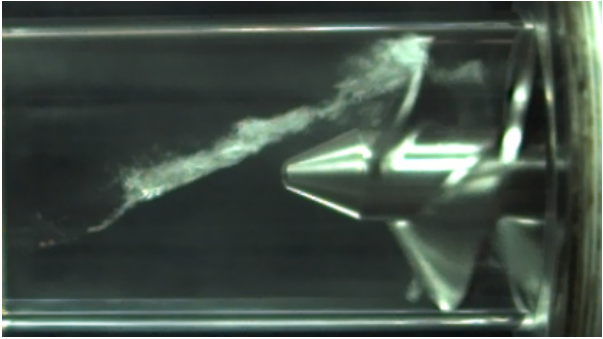

(b) $Q=0.17 Q_{d}$

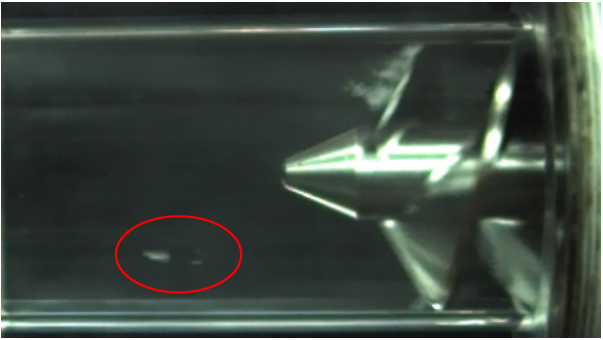

(d) $Q=0.3 Q_{d}$

Figure 9. Variation of vortex under NPSH $=10 \mathrm{~m}$.

\subsection{Cavitation Evolution in the Inducer with Different NPSH}

The high-speed pump was operated under different NPSH, in order to analyze the evolution of cavitation in the inducer. Visual experiments of different NPSH at $0.27 \mathrm{Q}_{\mathrm{d}}$ were conducted. The results at different inlet pressures were recorded, and Equation (8) is used to calculate the NPSH [32]:

$$
\mathrm{NPSH}=\frac{P_{i n}-P_{v}}{\rho g}
$$

where $P_{\text {in }}$ is the static pressure at inlet of the pump, $P_{v}$ is the saturated vapor pressure, $\rho$ is the liquid density, and $g$ is the gravitational acceleration.

The cavitation evolution in the inducer under different NPSH is shown in Figure 10. The cavitation evolution experienced three stages: initial, developing, and deteriorating stage [20]. According to Figure 10, when the NPSH is modified, a cavitation vortex occurred at the inlet pipe. As the inlet pressure of the pump decreased, the cavitation in the inlet pipe developed constantly, and the volume of the vortex gradually increased. When the NPSH dropped to $7.25 \mathrm{~m}$, the volume of the vortex in the inlet pipe slightly increased, but pressure at the outlet did not drop. This was the initial stage of cavitation.

Next, the inlet pressure of the pump dropped continually, and the cavitation gradually transitioned from the initial stage to the developing stage. When the NPSH dropped to $6.72 \mathrm{~m}$, the volume of cavitation in the inlet pipe suddenly increased, and the cavitation evolved to the developing stage. When the NPSH was $5.41 \mathrm{~m}$, the flow among the inducer was considerably unstable. The vortex presented an irregular divergence, and multiple backflow vortices occurred simultaneously. Subsequently, the vortexes gradually spread from the outer edge of the pipe to the center and extended to the entire leading edge of the inducer in the end. When the NPSH dropped to $3.81 \mathrm{~m}$, the volume of the bubble further increased and gathered at the center of the pipe. The cavitation fully developed, and the leading edge of the inducer was filled with large number of bubbles. However, the bubbles collapsed at the flow channel of the inducer due to being pressurized by the blades. According to the red circles in Figure 10e, there were no obvious bubbles in the flow 
channel near the outlet of the inducer. Furthermore, only a few bubbles entered the inlet of the main impeller. At this stage, the performance of the pump was not significantly modified.

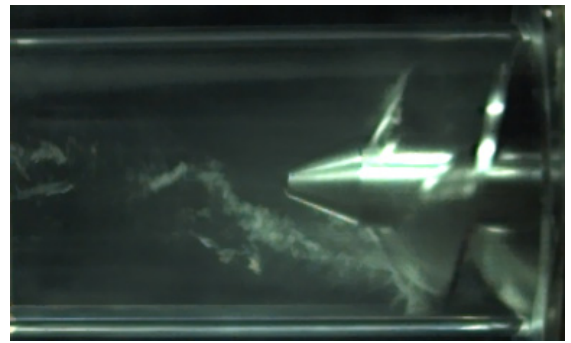

(a) $\mathrm{NPSH}=9.5 \mathrm{~m}$

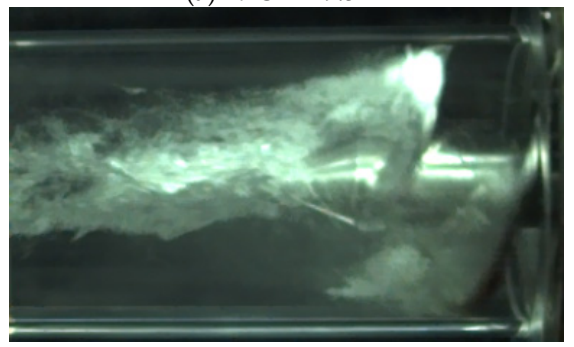

(c) $\mathrm{NPSH}=6.72 \mathrm{~m}$

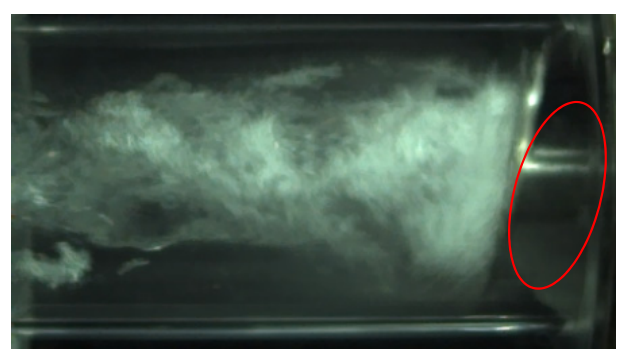

(e) $\mathrm{NPSH}=3.81 \mathrm{~m}$

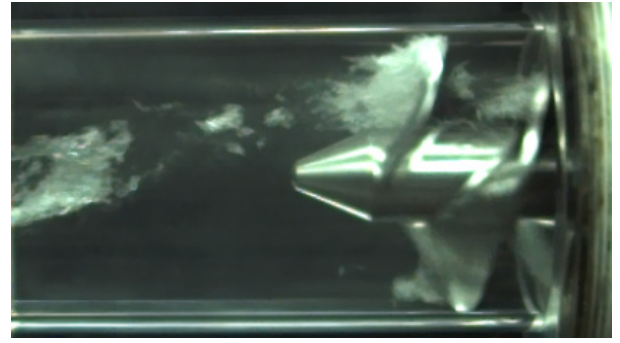

(b) $\mathrm{NPSH}=7.25 \mathrm{~m}$

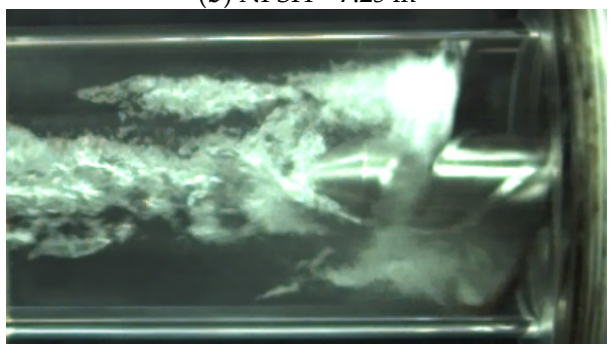

(d) $\mathrm{NPSH}=5.41 \mathrm{~m}$

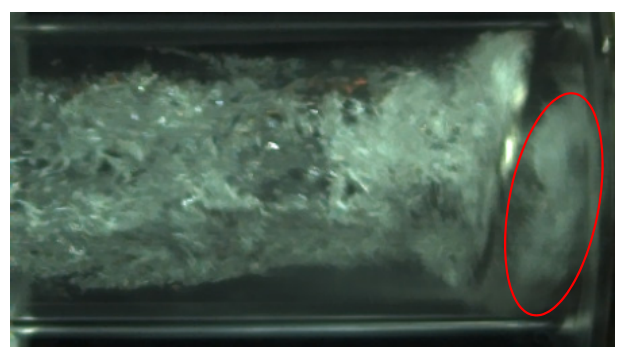

(f) $\mathrm{NPSH}=2.86 \mathrm{~m}$

Figure 10. Cavitation evolution in the inducer under $Q=0.27 Q_{d}$.

In the next stage, the inlet pressure of the pump further dropped, and the inducer cavitation transitioned from the developing stage to the deteriorating. When the NPSH was $2.86 \mathrm{~m}$, the volume of the cavitation significantly increased, the bubbles were almost filling the entire inlet pipe and extending to the flow channel of inducer. Based on Figure 10f, plenty of bubbles among the outlet of the inducer entered the main impeller. Bubbles accounted for the main impeller cavitate and a rapid decline of the pump performance.

According to Figure 10, bubbles in the inlet pipe increased as NPSH decreased, and the cavitation evolution in the inducer at $0.27 \mathrm{Q}_{\mathrm{d}}$ was different from the large flow condition. The backflow vortex disappeared when cavitation occurred under the design flow rate [18], while the backflow vortex extended into the inlet pipe at the low flow condition. With decrease in the NPSH, the volume of the backflow vortex increased continually until the vortex blocked the inlet pipe and the inducer flow channel, resulting in a rapid decline of the pump performance, rather than weakening or disappearing during this period. In addition, an obvious cavitation surge occurred in the high-speed pump when the cavitation evolved to the deteriorating stage.

According to Figure 9, when NPSH $=10 \mathrm{~m}$ and the flow rate was less than $0.3 \mathrm{Q}_{\mathrm{d}}$, there was an initial backflow vortex in the inlet pipe. Based on this result, it can be inferred that when the high-speed pump operated at the flow rate less than $0.3 Q_{d}$, the cavitation evolution was similar to Figure 10. 


\subsection{Analysis of Cavitation Asymmetry}

Under low flow rate conditions, the flow in the inducer is extremely unstable, which contributes to unstable cavitation in the inducer. The backflow vortex at the leading edge of the inducer developed in the upstream direction. Furthermore, only one backflow vortex was formed in the inlet pipe. This vortex extended from the inlet pipe to the leading edge of one of the inducer blades. The similar vortex was not detected on another blade, i.e., asymmetric cavitation occurred.

When $Q=0.14 Q_{d}$ and NPSH $=10 \mathrm{~m}$, the change of the position of the inducer and the vortex in the inlet pipe at different times is illustrated in Figure 11. Obviously, backflow vortex occurred in this condition. The vortex rotated with the inducer, and the shape of the vortex was not significantly altered. However according to Figure 11, the characteristics of vortex were not seemingly consistent with each other. In fact, this is a false appearance since the vortex rotated with the inducer. The position of the vortex was constantly altered at different moment while the position of the camera was fixed. Moreover, tip leakage cavitation at the outer edge of the blade was observed (at the position of the red circle). The cavitation on the two blades of the inducer was completely different for a fixed period and was asymmetrical.

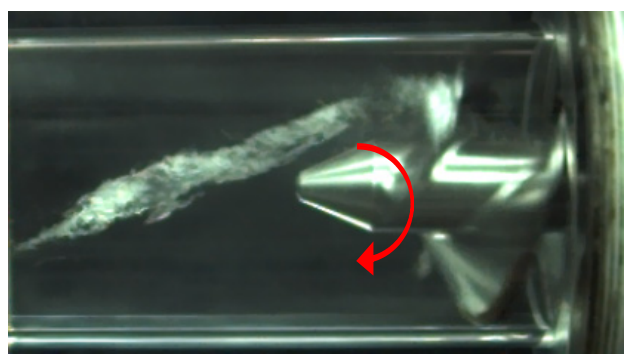

(a) $\mathrm{t}=0 \mathrm{~ms}$

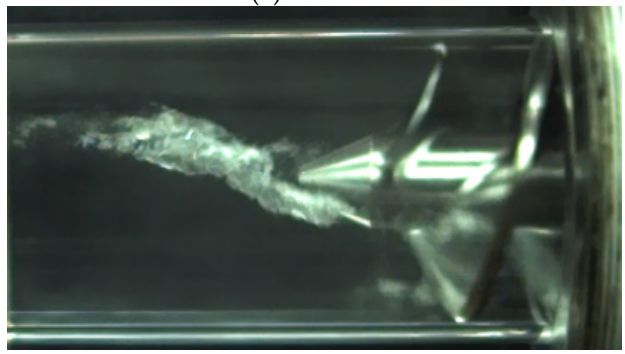

(c) $\mathrm{t}=6.35 \mathrm{~ms}$

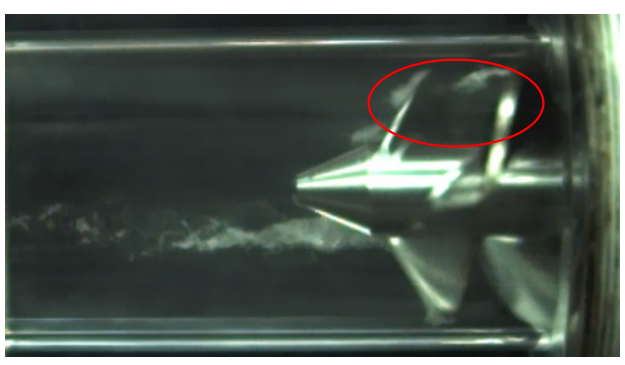

(e) $\mathrm{t}=13 \mathrm{~ms}$

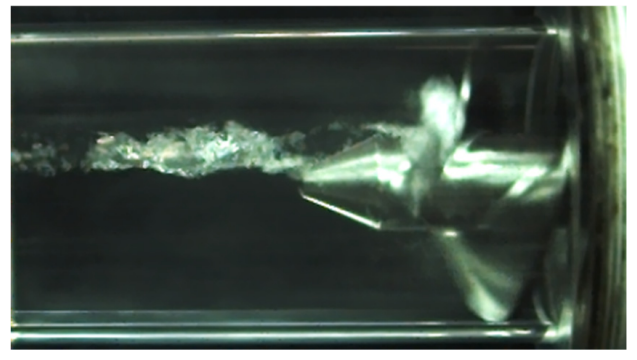

(b) $\mathrm{t}=3.68 \mathrm{~ms}$

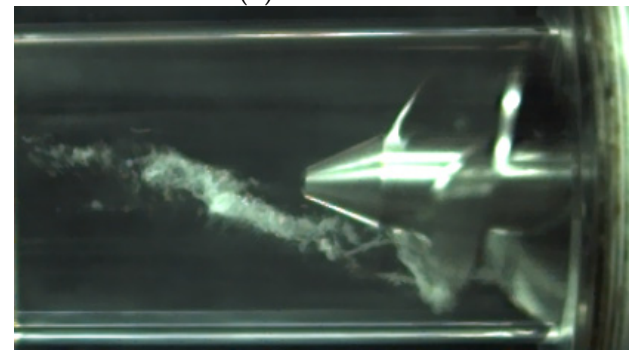

(d) $\mathrm{t}=9 \mathrm{~ms}$

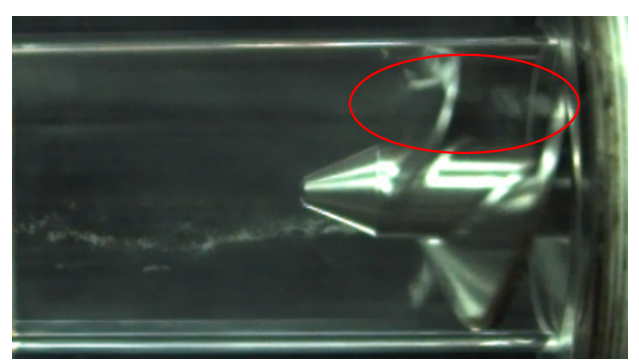

(f) $\mathrm{t}=14.35 \mathrm{~ms}$

Figure 11. Vortex distribution at different times $\left(Q=0.14 Q_{d}\right.$ and NPSH $\left.=10 \mathrm{~m}\right)$.

The rotational speed of the high-speed pump in this paper was $n=8000 \mathrm{rpm}$, and the rotation period of the inducer was $7.5 \mathrm{~ms}$. According to Figure 11, although the vortex in the inlet pipe rotated with the inducer, it was not synchronized. The inducer rotated approximately two cycles while the backflow vortex rotated less than a single cycle. The rotation period of the backflow vortex approached two times of the inducer, which is 
similar to Maekawa's conclusion [14]. In addition, while the vortex is rotating with the inducer in the inlet pipe, it also rotated around its axis [16].

Asymmetric cavitation phenomenon during the initial stage of cavitation in the inducer is shown in Figure 11. With the inlet pressure of the pump dropped, the cavitation in the inducer evolved to the developing stage. Then, the number of bubbles within the inlet pipe continued to increase. In Figure 12, vortex distribution under different NPSH is shown. When the NPSH dropped to $6.72 \mathrm{~m}$, the volume of the vortex in the inlet pipe increased but remained asymmetrical. The vortex extended from the inlet pipe to the leading edge of one blade. The tip leakage vortex cavitation also increased at the outer edge of the other blade (at the position of the red circle). With the pump inlet pressure dropped further, the cavitation in the inlet pipe did not present a single band again; instead, it started to diverge. Multiple backflow vortexes were scattered in the inlet pipe, and cavitation was attached to the leading edges of both inducer blades. When the NPSH dropped to $4.9 \mathrm{~m}$, the asymmetric characteristic of cavitation disappeared progressively. As the inlet pump pressure continued to drop, the volume of the bubbles increased significantly, almost blocking the pipe. Moreover, the phenomenon of cavitation asymmetry disappeared. Although the shape of the bubbles at different NPSH was varying, the rotational speed of the cavitation bubbles was still lower than the inducer.

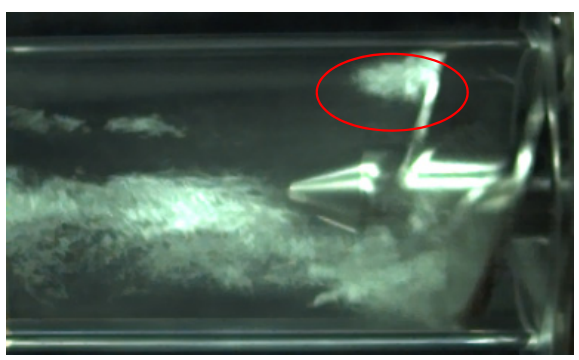

(a) $\mathrm{NPSH}=6.72 \mathrm{~m}, \mathrm{t}=0 \mathrm{~ms}$

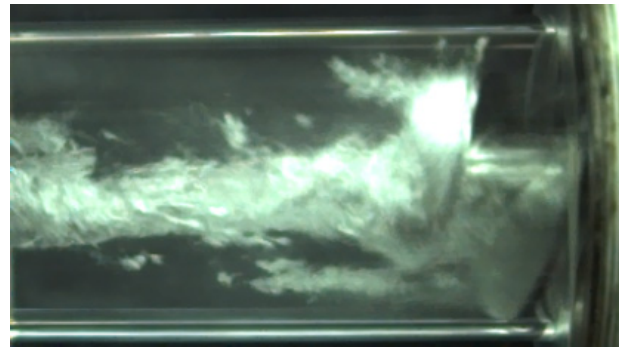

(c) $\mathrm{NPSH}=4.9 \mathrm{~m}, \mathrm{t}=7.53 \mathrm{~ms}$

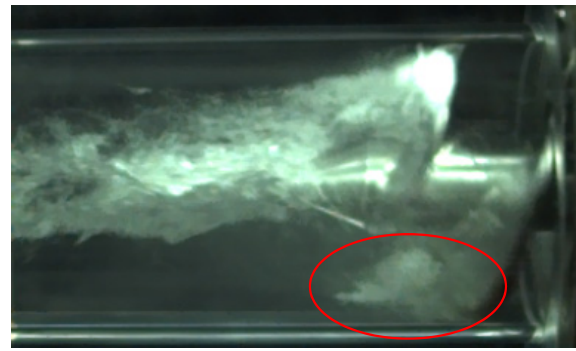

(b) $\mathrm{NPSH}=6.72 \mathrm{~m}, \mathrm{t}=8.46 \mathrm{~ms}$

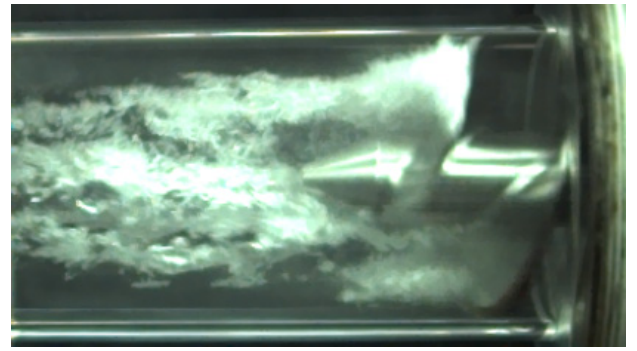

(d) $\mathrm{NPSH}=4.9 \mathrm{~m}, \mathrm{t}=10.86 \mathrm{~ms}$

Figure 12. Vortex distribution under different $\mathrm{NPSH}\left(\mathrm{Q}=0.27 \mathrm{Q}_{\mathrm{d}}\right)$.

\subsection{Comparison of Cavitation Performance}

The cavitation performance of the pump at the design flow rate and $0.27 \mathrm{Q}_{\mathrm{d}}$ are compared in Figure 13. The NPSH of the pump at the design flow rate was $2.14 \mathrm{~m}$, and the NPSH at the flow rate of $0.27 \mathrm{Q}_{\mathrm{d}}$ was $2.30 \mathrm{~m}$, the NPSH of $0.27 \mathrm{Q}_{\mathrm{d}}$ increased by $7.5 \%$ compared with the design flow. The cavitation performance of a high-speed pump under low flow rate conditions was directly related to the backflow vortex that appeared in the inlet pipe. With a decrease in the inlet pressure, the volume of the backflow vortex gradually increased. When the cavitation evolved to the deteriorating stage, many bubbles filled the inlet pipe, thus blocking the flow channel of the inducer. Moreover, many bubbles entered the main impeller, which induced the overall cavitation of the pump. 


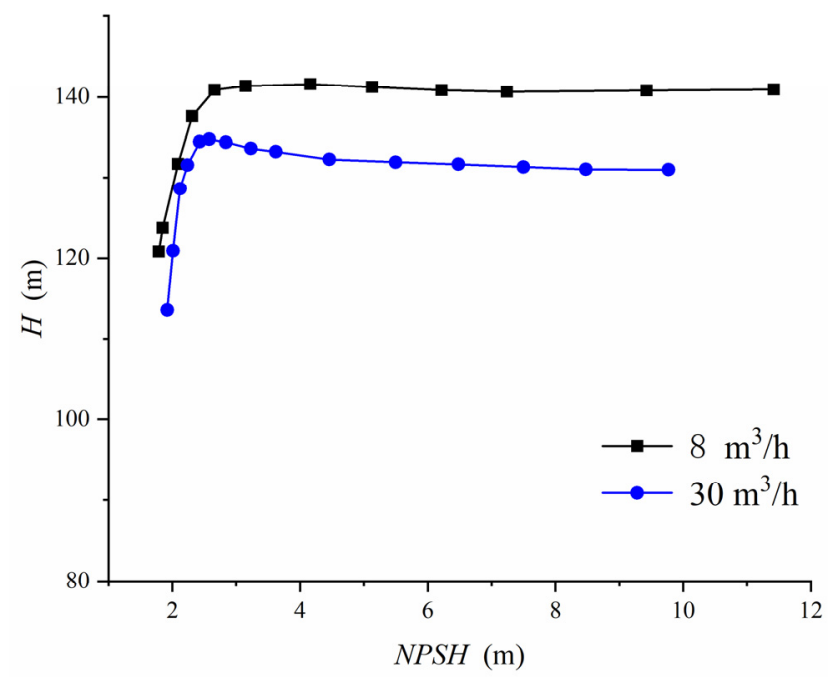

Figure 13. Cavitation performance curve of a high-speed magnetic pump.

\section{Conclusions}

Visual experiments of a high-speed inducer magnetic drive pump operating at $\mathrm{n}=8000 \mathrm{r} / \mathrm{min}$ were conducted. The cavitation evolution of the inducer under different conditions were captured. The following conclusions are drawn:

1. A band-shaped vertex appeared in the inlet pipe when the inducer operated under extremely low flow rate, which was at odds with the designed condition.

2. The backflow vortex in the inlet pipe rotated with the inducer. Furthermore, the rotational speed of the backflow vortex was approximately half of the inducer.

3. The volume of the backflow vortex decreased with the flow rate increase. When the flow rate increased to $0.3 \mathrm{Q}_{\mathrm{d}}$, the band-shaped vortex in the inlet pipe disappeared.

4. When the flow rate was $0.27 \mathrm{Q}_{\mathrm{d}}$ and NPSH was larger than $6.72 \mathrm{~m}$, cavitation was in the initial stage and was asymmetrical; when NPSH dropped to $5.41 \mathrm{~m}$, cavitation was in the developing stage and was less asymmetrical; when NPSH dropped to $3.81 \mathrm{~m}$, cavitation evolved to the deteriorating stage, plenty of bubbles entered the main impeller, resulting in full-scale cavitation and rapid decline of pump performance.

5. The cavitation performance under extremely low flow rate was worse than that of under design condition. The NPSH value of $0.27 Q_{d}$ was $7.5 \%$ greater than that of under design condition.

The current work only focuses on the cavitation evolution of inducer under low flow condition. In further research, a visual experiment of inducers under more various operating conditions will be carried out, in order to compare the difference of cavitation development of inducer under different flow conditions. Moreover, visual pictures are clearly not enough for several reasons in the current work. It is necessary to increase the number of LED light reflectors and select reasonable shooting parameters, including aperture and exposure time, etc. In addition, the surface of the inducer should be blackened to reduce the reflection in order to capture the bubble distribution more clearly.

Author Contributions: Conceptualization, Z.X.; Methodology, Z.X.; Software, K.Z.; Validation, H.Z. Formal Analysis, Z.X.; Investigation, J.W.; Resources, K.Z.; Data Curation, H.Z.; Writing-Original Draft Preparation, Z.X.; Writing-Review \& Editing, Z.X.; Supervision, J.W.; Project Administration, F.K.; Funding Acquisition, N.Q. All authors have read and agreed to the published version of the manuscript.

Funding: This work is supported by National Natural Science Foundation of China (No. 51806082) and Jiangsu Province's Key Research and Development Program of China (No. BE2018085), the authors express their gratitude for their support.

Conflicts of Interest: The authors declare no conflict of interest. 


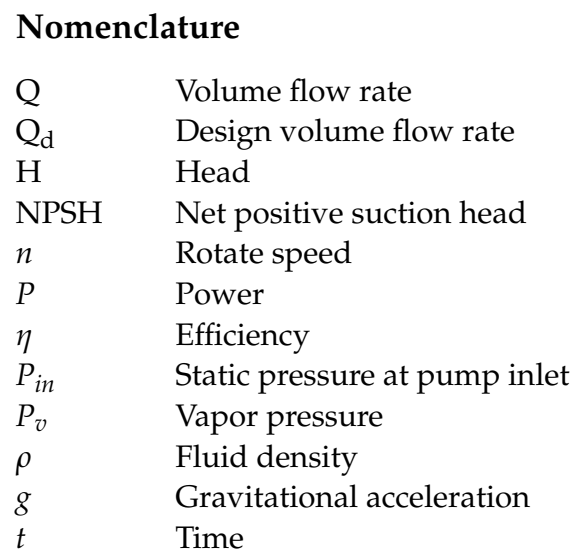

\section{References}

1. Bakir, F.; Kouidri, S.; Noguera, R.; Rey, R. Experimental Analysis of an Axial Inducer Influence of the Shape of the Blade Leading Edge on the Per-formances in Cavitating Regime. J. Fluids Eng. 2003, 125, 293-301. [CrossRef]

2. Coutier-Delgosha, O.; Caignaert, G.; Bois, G.; Leroux, J.-B. Influence of the Blade Number on Inducer Cavitating Behavior. J. Fluids Eng. 2012, 134, 081304. [CrossRef]

3. Cheng, X.; Li, Y.; Zhang, S. Effect of inlet sweepback angle on the cavitation performance of an inducer. Eng. Appl. Comput. Fluid Mech. 2019, 13, 713-723. [CrossRef]

4. Okita, K.; Ugajin, H.; Matsumoto, Y. Numerical Analysis of the Influence of the Tip Clearance Flows on the Unsteady Cavitating Flows in a Three-Dimensional Inducer. J. Hydrodyn. 2009, 21, 34-40. [CrossRef]

5. Hong, S.-S.; Kim, J.-S.; Choi, C.-H.; Kim, J. Effect of Tip Clearance on the Cavitation Performance of a Turbopump Inducer. J. Propuls. Power 2006, 22, 174-179. [CrossRef]

6. Kim, S.; Choi, C.; Kim, J.; Park, J.; Baek, J. Tip Clearance Effects on Cavitation Evolution and Head Breakdown in Turbopump Inducer. J. Propuls. Power 2013, 29, 1357-1366. [CrossRef]

7. Franc, J.-P.; Rebattet, C.; Coulon, A. An Experimental Investigation of Thermal Effects in a Cavitating Inducer. J. Fluids Eng. 2004, 126, 716-723. [CrossRef]

8. Ehrlich, D.A.; Murdock, J.W. A Dimensionless Scaling Parameter for Thermal Effects on Cavitation in Turbopump Inducers. J. Fluids Eng. 2015, 137, 041103. [CrossRef]

9. Guo, X.; Zhu, Z.; Cui, B.; Li, Y. Effects of the short blade locations on the anti-cavitation performance of the splitter-bladed inducer and the pump. Chin. J. Chem. Eng. 2015, 23, 1095-1101. [CrossRef]

10. Choi, Y.-D.; Kurokawa, J.; Imamura, H. Suppression of Cavitation in Inducers by J-Grooves. J. Fluids Eng. 2006, 129, 15-22. [CrossRef]

11. Pace, G.; Valentini, D.; Pasini, A.; Hadavandi, R.; D'Agostino, L. Analysis of Flow Instabilities on a Three-Bladed Axial Inducer in Fixed and Rotating Frames. J. Fluids Eng. 2018, 141. [CrossRef]

12. Lettieri, C.; Spakovszky, Z.; Jackson, D.; Schwille, J. Characterization of Cavitation Instabilities in a Four-Bladed Turbopump Inducer. J. Propuls. Power 2018, 34, 510-520. [CrossRef]

13. Xiang, L.; Tan, Y.; Chen, H.; Xu, K. Experimental investigation of cavitation instabilities in inducer with different tip clearances Chin. J. Aeronaut. 2021, 34, 168-177. [CrossRef]

14. Tsujimoto, Y.; Yoshida, Y.; Maekawa, Y.; Watanabe, S.; Hashimoto, T. Observations of Oscillating Cavitation of an Inducer. J. Fluids Eng. 1997, 119, 775-781. [CrossRef]

15. Ito, Y.; Sato, Y.; Nagasaki, T. Theoretical Analyses of the Number of Backflow Vortices on an Axial Pump or Compressor. J. Fluids Eng. 2020, 142. [CrossRef]

16. Yamanishi, N.; Fukao, S.; Qiao, X.; Kato, C.; Tsujimoto, Y. LES Simulation of Backflow Vortex Structure at the Inlet of an Inducer. J. Fluids Eng. 2007, 129, 587-594. [CrossRef]

17. Tani, N.; Yamanishi, N.; Tsujimoto, Y. Influence of Flow Coefficient and Flow Structure on Rotational Cavitation in Inducer. J. Fluids Eng. 2012, 134, 021302. [CrossRef]

18. Choi, C.-H.; Kim, J. Study on the Cavitating Flows in a Turbopump Inducer. J. Propuls. Power 2015. [CrossRef]

19. Cui, B.; Cai, M.; Li, Y. Influence of air-water two-phase flow on the performance of a high-speed inducer. Proc. Inst. Mech. Eng. Part E J. Process. Mech. Eng. 2020, 234, 588-599. [CrossRef]

20. Huan, Y.-Y.; Liu, Y.-Y.; Li, X.-J.; Zhu, Z.-C.; Qu, J.-T.; Zhe, L.; Han, A.-D. Experimental and numerical investigations of cavitation evolution in a high-speed centrifugal pump with inducer. J. Hydrodyn. 2021, 33, 140-149. [CrossRef]

21. Ito, Y.; Tsunoda, A.; Kurishita, Y.; Kitano, S.; Nagasaki, T. Experimental Visualization of Cryogenic Backflow Vortex Cavitation with Thermodynamic Effects. J. Propuls. Power 2016, 32, 71-82. [CrossRef]

22. Zhang, D.; Shi, W.; Pan, D.; Dubuisson, M. Numerical and Experimental Investigation of Tip Leakage Vortex Cavitation Patterns and Mechanisms in an Axial Flow Pump. J. Fluids Eng. Trans. ASME 2015, 137, 121103. [CrossRef] 
23. Guo, X.; Zhu, Z.; Cui, B.; Huang, Y. Anti-cavitation performance of a splitter-bladed inducer under different flow rates and different inlet pres-sures. Sci. China Technol. Sci. 2015, 58, 2131-2138. [CrossRef]

24. Zwart, P.J.; Gerber, A.G.; Belamri, T. A two-phase flow model for predicting cavitation dynamics. In Proceedings of the Fifth In-ternational Conference on Multiphase Flow, Yokohama, Japan, 30 May-4 June 2004; Volume 152.

25. Al-Obaidi, A.R. Investigation of the influence of various numbers of impeller blades on internal flow field analysis and the pressure pulsation of an axial pump based on transient flow behavior. Heat Transf. 2020, 49, 2000-2024. [CrossRef]

26. Al-Obaidi, A.R. Numerical Investigation of Flow Field Behaviour and Pressure Fluctuations within an Axial Flow Pump under Transient Flow Pattern Based on CFD Analysis Method. J. Phys. Conf. Ser. 2019, 1279. [CrossRef]

27. Al-Obaidi, A.R. Monitoring the Performance of Centrifugal Pump under Single-Phase and Cavitation Condition: A CFD Analysis of the Number of Impeller Blades. J. Appl. Fluid Mech. 2019, 12, 445-459. [CrossRef]

28. Al-Obaidi, A.R.; Mohammed, A. Numerical Investigations of Transient Flow Characteristic in Axial Flow Pump and Pressure Fluctuation Analysis Based on the CFD Technique. J. Eng. Sci. Technol. Rev. 2019, 12, 70-79. [CrossRef]

29. Al-Obaidi, A.R. Numerical investigation on effect of various pump rotational speeds on performance of centrifugal pump based on CFD analysis technique. Int. J. Model. Simul. Sci. Comput. 2021, 12. [CrossRef]

30. Al-Obaidi, A.R. Analysis of the Effect of Various Impeller Blade Angles on Characteristic of the Axial Pump with Pressure Fluctuations Based on Time- and Frequency-Domain Investigations. Iran. J. Sci. Technol. Trans. Mech. Eng. 2021, 45, 441-459. [CrossRef]

31. Al-Obaidi, A.R. Effects of Different Turbulence Models on Three-Dimensional Unsteady Cavitating Flows in the Centrifugal Pump and Performance Prediction. Int. J. Nonlinear Sci. Numer. Simul. 2019, 20, 487-509. [CrossRef]

32. Al-Obaidi, A.R. Detection of Cavitation Phenomenon within a Centrifugal Pump Based on Vibration Analysis Technique in both Time and Frequency Domains. Exp. Tech. 2020, 44, 329-347. [CrossRef] 